\title{
Aspectos bioquímicos da resistência do algodoeiro à ramulose potencializada pelo silício
}

\author{
Antonia Mirian Nogueira de Moura Guerra (1); Fabrício Ávila Rodrigues (2*); Paulo Geraldo Berger ( ${ }^{3}$ ); \\ Angélica Fátima Barros ( $\left.{ }^{2}\right)$; Yasmim Cristina Rodrigues da Silva ( $\left.{ }^{2}\right)$; Tricia Costa Lima $\left({ }^{4}\right)$ \\ (') Universidade Federal do Oeste do Pará (UFOPA), Instituto de Biodiversidade e Florestas, 68035-110 Santarém (PA), Brasil. \\ (2) Universidade Federal de Viçosa (UFV), Departamento de Fitopatologia, 36570-000 Viçosa (MG), Brasil. \\ (3) UFV, Departamento de Fitotecnia, 36570-000 Viçosa (MG), Brasil. \\ (4) Universidade Estadual de Goiás (UEG), Departamento de Fitotecnia, Campus Palmeiras de Goiás, 76190-000 Palmeiras de Goiás (GO), Brasil. \\ (*) Autor correspondente: fabricio@ufv.br
}

Recebido: 14/abr./2013; Aceito: 2/ago./2013

\section{Resumo}

Objetivou-se avaliar o efeito do silício (Si) sobre a ramulose e aspectos bioquímicos da resistência do algodoeiro a essa doença. Os cultivares BRS Araçá e FM 993 foram desenvolvidos em solução nutritiva contendo (+Si) ou não (-Si) silício. Avaliou-se o período de incubação (PI), incidência (I), área abaixo da curva do índice da ramulose (AACIR) e concentração foliar de Si (CFSi). A CFSi e o PI aumentaram em 76\% e 19,5\%, respectivamente, nas plantas +Si em relação às -Si, e a I e a AACIR diminuíram em $64 \%$ e 18\%, respectivamente. A concentração dos compostos fenólicos solúveis totais (CFST) e dos derivados da lignina-ácido tioglicólico (DLATG) dos dois cultivares supridos com Si aumentou durante o progresso da ramulose, porém essa concentração foi inferior à daquelas que não receberam Si. No cultivar BRS Araçá +Si a atividade das enzimas quitinase (QUI) e glicanase (GLI) aumentou até os 10 dai em relação às plantas -Si. A atividade das enzimas peroxidase (POX) e polifenoloxidase (PPO) no cultivar BRS Araçá +Si aumentou entre 20 e 30 dai em relação às plantas -Si, enquanto na FM 993 +Si o aumento foi de até 10 dai. No cultivar FM 993 +Si, a atividade da fenilalanina amônia-liase (FAL) aumentou. O fornecimento de Si às plantas de algodoeiro aumentou a resistência à ramulose mediante incremento na concentração CFST e de DLATG nos dois cultivares e na atividade das POX, PPO, QUI e GLI na BRS Araçá, e de POX e FAL na FM 993.

Palavras-chave: bioquímica, compostos de defesa, enzimas, Colletotrichum gossypii var. cephalosporioides, resistência.

\section{Biochemical aspects of resistance to cotton ramulosis powered by silicon}

\begin{abstract}
The aim of this study was to evaluate the effect of using silicon ( $\mathrm{Si}$ ) on the control and biochemical aspects of cotton resistance to ramulosis. Cotton plants of BRS Araçá and FM 993 were grown in nutrient solution containing (+Si) or not (-Si) silicon. We evaluated the incubation period (PI), the incidence (I), the area under the curve of index ramulosis (AACIR) and leaf concentration of Si (CESi). The CESi and PI increased by $76 \%$ and $19.5 \%$ in plants supplied with Si relative to the -Si and the AACIR decreased by $64 \%$ and $18 \%$, respectively. The concentration of total soluble phenolics (CFST) and derivatives of lignin-thioglycolic acid (DLATG) in plants of both cultivars supplied with Si increased during the progress of ramulosis, but were lower as compared to plants that did not receive Si. In BRS Araçá supplied with Si, the activity of the enzymes chitinase (QUI) and glucanase (GLI) increased until 10 days after inoculation (dai) compared to -Si plants. The activity of peroxidase (POX) and polyphenol oxidase (PPO) in BRS Araçá supplied with Si increased between 20 and 30 dai with regard to plants -Si, while FM 993 supplied with Si presented increases in the activity of PPO and POX up to 10 dai. In FM 993 supplied with Si there was no increase in the activity of phenylalanine ammonia-lyase (FAL). The supply of Si to cotton plants increased resistance to ramulose by increasing the concentration CFST and DLATG in both cultivars, and the activities of POX, PPO, QUI and GLU in BRS Araçá, and POX and FAL in FM 993.
\end{abstract}

Key words: biochemistry, defense compounds, enzymes, Colletotrichum gossypii var. cephalosporioides, resistance. 


\section{INTRODUÇÃO}

Dentre as doenças que afetam a cultura do algodoeiro, a ramulose, causada por Colletotrichum gossypii var. cephalosporioides A. S. Costa, destaca-se por causar perdas de até $85 \%$ na produção (Suassuna e Coutinho, 2011). O fungo C. gossypii var. cephalosporioides infecta as folhas, pecíolos e caule, provocando nanismo e superbrotamento dos ramos, o que prejudica a formação das maçãs e, consequentemente, o rendimento do algodoeiro (МентA et al., 2005).

Durante a interação patógeno-hospedeiro, ocorre uma série de eventos bioquímicos que levam à ativação de defesas por parte da planta, resultando na produção de compostos que podem ser tóxicos aos patógenos ou apenas restringir seu desenvolvimento (WróbeL-KwIATKOWsKa et al., 2004). A principal estratégia de controle dessa doença é a química, visto que a maioria dos cultivares de algodão não possui resistência genética a essa doença (Suassuna e Coutinho, 2011).

$\mathrm{O}$ silício $(\mathrm{Si})$, apesar de não ser considerado essencial para o crescimento das plantas, pode ser absorvido em níveis que excedem os macronutrientes, por exemplo, em arroz (EPSTEIN, 1999). Essencial ou não, o papel do Si nas plantas tem sido cada vez mais de interesse dos pesquisadores devido a seus inúmeros benefícios, principalmente quando as plantas estáo sob estresse. Do ponto de vista morfológico, a deposição e polimerização do ácido monossilícico abaixo da cutícula forma uma camada dupla cutícula-sílica (YosHIDA, 1965). Isso impede ou atrasa a penetraçáo de alguns patógenos (KIM et al., 2002). Outro mecanismo proposto é que o Si solúvel tem um papel ativo que potencializa mecanismos de defesa das plantas com o aumento na produção de compostos fenólicos, nos níveis de algumas classes de fitoalexinas e também na ativação de alguns genes que codificam proteínas PR (CHÉRIF et al., 1994; Rodrigues et al., 2003; 2004; 2005). Além disso, o incremento na atividade de enzimas líticas na parede celular fúngica ou associada com o metabolismo secundário da planta (Liang et al., 2005) reforçam a hipótese de que o Si potencializa mecanismos de defesa em plantas e não atua apenas de forma passiva na resistência. Em pepineiros, a aplicação foliar com Si controlou o míldio pulverulento mas não foi capaz de potencializar a atividade das enzimas peroxidases, polifenoloxidases e quitinases, ao contrário do obtido em plantas supridas com $\mathrm{Si}$ via solo, onde o controle da doença, além de ser efetivo, esteve associado com aumento na atividade dessas enzimas durante o processo infeccioso (Liang et al., 2005). No entanto, a exata natureza da interação entre o Si solúvel e as vias bioquímicas de defesa da planta permanece desconhecida. Em todo caso, o uso de Si como uma medida alternativa de controle vem ganhando cada vez mais aceitação e é promissor para os produtores considerando os enormes prejuízos que as diferentes doenças têm causado na produçáo das mais diversas culturas.

Não existem informaçôes na literatura científica sobre o efeito de Si na redução da intensidade da ramulose em algodoeiros e sobre os possíveis mecanismos bioquímicos envolvidos na resistência. Assim, objetivou-se avaliar o efeito do silício $(\mathrm{Si})$ sobre na resistência do algodoeiro à ramulose e aspectos bioquímicos da resistência da planta a essa doença.

\section{MATERIAL E MÉTODOS}

\section{Preparo da solução nutritiva e crescimento das plantas de algodão}

Sementes de algodão dos cultivares BRS Araçá e FM 993 foram lavadas em solução de hipoclorito de sódio (10\%) por dois minutos, seguidas de lavagem em água destilada por três minutos e germinadas em leito de areia lavada e autoclavada. Dez dias após a germinação, três plântulas foram transferidas para vasos plásticos de cinco litros contendo soluçáo nutritiva de Hoagland e Arnon (1950) modificada, constituída de: $6,0 \mathrm{mmol} \mathrm{L}^{-1} \mathrm{KNO}_{3} ; 1,0 \mathrm{mmol} \mathrm{L}^{-1} \mathrm{NH}_{4} \mathrm{H}_{2} \mathrm{PO}_{4} ; 2,0 \mathrm{mmol} \mathrm{L}^{-1}$ $\mathrm{MgSO}_{4} \cdot 7 \mathrm{H}_{2} \mathrm{O} ; 4,0 \mathrm{mmol} \mathrm{L}-1 \mathrm{Ca}\left(\mathrm{NO}_{3}\right)_{2} ; 0,3 \mu \mathrm{mol} \mathrm{L}^{-1}$ $\mathrm{CuSO}_{4} \cdot 5 \mathrm{H}_{2} \mathrm{O} ; 1,3 \mu \mathrm{mol} \mathrm{L}^{-1} \mathrm{ZnSO}_{4} .7 \mathrm{H}_{2} \mathrm{O} ; 46 \mu \mathrm{mol} \mathrm{L}^{-1}$ $\mathrm{H}_{3} \mathrm{BO}_{3} ; 12,6 \mu \mathrm{mol} \mathrm{L}^{-1} \mathrm{MnCl}_{2} .4 \mathrm{H}_{2} \mathrm{O} ; 0,1 \mu \mathrm{mol} \mathrm{L}^{-1}$ $\left(\mathrm{NH}_{4}\right)_{6} \mathrm{Mo}_{7} \mathrm{O}_{24} \cdot 4 \mathrm{H}_{2} \mathrm{O} ; 45 \mu \mathrm{mol} \mathrm{L}{ }^{-1} \mathrm{FeSO}_{4} .7 \mathrm{H}_{2} \mathrm{O}-\mathrm{EDTA}$ bissódico. Ácido monossilícico obtido pela passagem do silicato de potássio através de uma coluna contendo resina trocadora de cátions (Amberlite IRA 410) (Ma e TAKAHASHI, 2002) foi adicionado à solução nutritiva nas concentraçóes de $0(-\mathrm{Si})$ e $2 \mathrm{mmol} \mathrm{Si} \mathrm{L}^{-1}(+\mathrm{Si})$. Foi utilizada soluçấo nutritiva a meia força iônica, incluindo a adição ou não do ácido monossilícico. Após sete dias, a concentração da solução utilizada foi modificada para força total. A soluçáo nutritiva foi aerada, trocada a cada quatro dias e o $\mathrm{pH}$ foi verificado diariamente e mantido entre 5,5 e 6,0.

\section{Obtenção do inóculo de C. gossypii var. cephalosporioides e inoculação das plantas}

As plantas de algodoeiro foram inoculadas com o isolado CNPA 0053 de C. gossypii var. cephalosporioides fornecido pela Embrapa Centro Nacional de Pesquisa do Algodão. O isolado de C. gossypii var. cephalosporioides foi armazenado em tubos de ensaio contendo meio batata-dextrose-ágar (BDA). O isolado foi repicado para placas de Petri contendo meio BDA e as placas foram transferidas para câmara de crescimento tipo B.O.D. com fotoperíodo de $12 \mathrm{~h}$ e temperatura de $25^{\circ} \mathrm{C}$, onde permaneceram por até 15 dias, até ocorrer abundante produção de conídios. O inóculo foi preparado adicionando-se $10 \mathrm{~mL}$ de água destilada em cada placa e fazendo-se uma raspagem superficial com pincel de cerdas macias para liberaçáo dos conídios. A suspensão obtida foi filtrada em gaze e ajustada para a concentração de $1,5 \times 10^{6}$ conídios $\mathrm{mL}^{-1}$ pela contagem em hemacitômetro. Para aumentar a aderência dos conídios sobre o tecido da planta, 
a suspensão foi preparada utilizando água contendo gelatina a $1 \%$ (p:v), além da adição de Tween $20(0,1 \mathrm{~mL} / 100 \mathrm{~mL}$ de suspensão), para quebrar a tensão superficial da água.

Plantas de algodoeiro no estádio V5 (40 dias após transplantio) (Marur e RuANo, 2001) foram inoculadas com C. gossypii var. cephalosporioides utilizando-se atomizador (VLS-Set Airbrush, Paache Airbrush Company, EUA). Após a inoculação, as plantas foram transferidas para câmara de nevoeiro com temperatura de $25 \pm 2^{\circ} \mathrm{C}$ e umidade relativa de $90 \pm 5 \%$, com fluxo contínuo de luz por $24 \mathrm{~h}$ e, em seguida, transferidas para câmara de crescimento com temperatura entre $25^{\circ} \mathrm{C}$ e $35^{\circ} \mathrm{C}$ e umidade relativa de $50 \pm 5 \%$, onde permaneceram até o final das avaliaçóes.

\section{Avaliação do período de incubação (PI), incidência e severidade da ramulose}

Em cada vaso foram marcadas cinco plantas para avaliação do PI, a partir das 24 horas após inoculação (hai). Avaliou-se a incidência (\%) da ramulose no quinto dia após a inoculação (dai) contando-se o número de plantas por vaso que apresentavam sintomas da ramulose. Para avaliar a severidade da ramulose foi utilizada a escala de notas proposta por Costa e FraGa JÚNIOR (1937), em que: 0 = plantas sem sintomas; $1=$ plantas apresentando lesóes necróticas nas folhas, pecíolos e nervuras; 2 = morte do ápice, hiperplasia e morte dos meristemas laterais; 3 = encurtamento dos internódios e início do superbrotamento; e 4 = intenso superbrotamento e redução do porte e desenvolvimento da planta, morte das partes afetadas. A severidade foi avaliada aos 10, 20 e 30 dai. As notas de severidade foram usadas para calcular o índice da ramulose (IR) de acordo com Mckinney (1923), para quem IR $=[$ (nota da doença $\times$ número de plantas com essa nota)/(número total de plantas $\times$ nota máxima da doença na escala) $] \times 100$. Os valores do IR para as repetiçóes de cada tratamento foram utilizados para calcular a área abaixo da curva do índice da ramulose (AACIR) de acordo com a fórmula proposta por SHANER e FinNEY (1977).

\section{Determinação da concentração de compostos fenólicos solúveis totais (CFST)}

Amostras de folhas foram coletadas em nitrogênio líquido e imediatamente armazenadas em ultrafreezer a $-80^{\circ} \mathrm{C}$ até análise. Amostras de $0,1 \mathrm{~g}$ foram maceradas em nitrogênio líquido. O macerado foi homogeneizado com $1,5 \mathrm{~mL}$ de metanol $80 \%$ e extraído durante $12 \mathrm{~h}$ em mesa agitadora orbital $(150 \mathrm{rpm})$, a temperatura ambiente $\left(-25^{\circ} \mathrm{C}\right)$. Os tubos foram cobertos com papel alumínio para proteger o extrato metanólico da oxidação pela luz. O extrato metanólico verde-escuro foi centrifugado a $12.000 \mathrm{~g}$ por $5 \mathrm{~min}$ e, após centrifugaçáo, o sobrenadante foi transferido pra um novo tubo e o resíduo mantido a $-80^{\circ} \mathrm{C}$, para determinaçáo da concentração dos derivados da lignina-ácido tioglicólico. A metodologia proposta por ZiesLin e Ben-ZaKen (1993), com algumas modificações, foi usada para determinação da concentração de CFST. Adicionaram-se $150 \mu \mathrm{L}$ do reagente Folin \& Ciocalteau's Phenol 0,25 M (Sigma-Aldrich, São Paulo, SP, Brasil) a $150 \mu \mathrm{L}$ do extrato metanólico. A mistura foi homogeneizada e mantida a temperatura ambiente $\left(\sim 25^{\circ} \mathrm{C}\right)$ por $5 \mathrm{~min}$. Posteriormente, $150 \mu \mathrm{L}$ de carbonato de sódio $1 \mathrm{M}$ foi adicionado à mistura, a qual foi homogeneizada novamente e mantida a temperatura ambiente. Após $10 \mathrm{~min}$, adicionou-se $1 \mathrm{~mL}$ de água destilada à mistura, que permaneceu em temperatura ambiente $\left(25^{\circ} \mathrm{C}\right)$ por 30 min. A absorbância das amostras foi medida a $725 \mathrm{~nm}$. A concentração de CFST foi expressa em mg de compostos fenólicos (expresso em catecol) por kg de folha fresca.

\section{Determinação da concentração dos derivados da lignina-ácido tioglicólico (DLATG)}

Adicionou-se 1,5 mL de água estéril ao resíduo obtido após a extração dos CFST. Após a homogeneização, a mistura foi centrifugada a $12.000 \mathrm{~g}$ por $5 \mathrm{~min}$. O sobrenadante foi descartado e o resíduo foi seco a $65^{\circ} \mathrm{C}$ por aproximadamente 12 h. O resíduo alcoólico-insolúvel seco, contendo lignina e ácidos fenólicos associados à parede celular, foi usado para determinação da lignina de acordo com a metodologia de BARBER e Ride (1988). Um volume de $1,5 \mathrm{~mL}$ da solução de ácido tioglicólico (Sigma-Aldrich, São Paulo, SP, Brasil) e $\mathrm{HCl} 2 \mathrm{~N}$ (1:10) foi adicionado ao resíduo seco. Os tubos foram levemente agitados para hidratar o resíduo e, em seguida, colocados em banho-maria $\left(100^{\circ} \mathrm{C}\right)$. Após $4 \mathrm{~h}$, os tubos foram colocados no gelo por 10 minutos. A mistura foi centrifugada a $12.000 \mathrm{~g}$ por $10 \mathrm{~min}$, o sobrenadante foi descartado e o precipitado foi lavado com $1,5 \mathrm{~mL}$ de água destilada estéril e a seguir centrifugado a $10.000 \mathrm{~g}$ por $10 \mathrm{~min}$. Após a centrifugação, o sobrenadante foi descartado e o precipitado ressuspendido em $1,5 \mathrm{~mL}$ de $\mathrm{NaOH}$ 0,5 M. A mistura foi agitada em mesa agitadora orbital $(150 \mathrm{rpm})$ a temperatura ambiente $\left(25^{\circ} \mathrm{C}\right)$ por $12 \mathrm{~h}$, depois centrifugada a $10.000 \mathrm{~g}$ por $10 \mathrm{~min}$ : o sobrenadante foi transferido para um novo tubo. Após a adição de $200 \mu \mathrm{L}$ de HCL concentrado ao sobrenadante, os tubos foram transferidos para uma bandeja com gelo e mantidos na geladeira $\left(4^{\circ} \mathrm{C}\right)$ por $4 \mathrm{~h}$, para precipitaçáo dos DLATG. Após a centrifugação a $10.000 \mathrm{~g}$ por $10 \mathrm{~min}$, o sobrenadante foi descartado e o precipitado, de cor laranja amarronzada, foi dissolvido em $2 \mathrm{~mL}$ de $\mathrm{NaOH} 0,5 \mathrm{M}$. A leitura da absorbância foi realizada a $290 \mathrm{~nm}$. A concentração dos DLATG foi expressa em mg kg${ }^{-1}$ de folha fresca utilizando-se uma curva padrão obtida com diferentes concentraçốes de lignina alcalina, éter 2-hidroxipropil (Sigma-Aldrich, São Paulo, SP, Brasil). 


\section{Determinação da atividade de enzimas de defesa}

Amostras da folha índice das plantas foram coletadas aos 5, 10, 20 e 30 dai. Amostras de folhas coletadas de plantas não inoculadas com C. gossypii var. cephalosporioides $(0 \mathrm{~h})$ serviram como controle. As amostras foram mantidas em $\mathrm{N}_{2}$ líquido durante a coleta e armazenadas em ultrafreezer a $-80^{\circ} \mathrm{C}$ até serem analisadas.

\section{Atividade de peroxidases (POX, EC 1.11.1.7)}

O extrato enzimático foi obtido pela maceração de $0,2 \mathrm{~g}$ de folhas em $\mathrm{N}_{2}$ líquido seguida de homogeneização em $2 \mathrm{~mL}$ do meio de extração composto de $0,1 \mathrm{M}$ tampáo fosfato

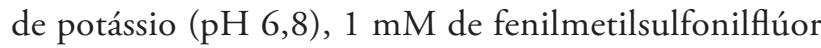
(PMSF), 0,1 mM de ácido etilenodiamino tetra-acético (EDTA) e $200 \mathrm{mg}$ de polivinilpolipirrolidona (PVPP). O homogeneizado foi centrifugado a $12.000 \mathrm{~g}$ por $15 \mathrm{~min}$ a $4^{\circ} \mathrm{C}$ e o sobrenadante foi utilizado no ensaio enzimático. A atividade da POX foi determinada conforme metodologias propostas por Chance e Maehley (1955) e Kar e Mishra (1976). No ensaio colorimétrico, utilizaram-se pirogalol e peróxido de hidrogênio como substratos. Para a reação foram adicionados $340 \mu \mathrm{L}$ de água destilada, $250 \mu \mathrm{L}$ do tampão fosfato de potássio $100 \mathrm{mM}(\mathrm{pH}$ 6,8), $200 \mu \mathrm{L}$ de pirogalol $100 \mathrm{mM}, 200 \mu \mathrm{L}$ de peróxido de hidrogênio $100 \mathrm{mM}$ e $10 \mu \mathrm{L}$ do extrato. As leituras de absorbância foram realizadas a $420 \mathrm{~nm}$ a cada $10 \mathrm{~s}$ durante um minuto. A atividade da POX foi medida utilizando-se para os cálculos o coeficiente de extinção molar 2,47 $\mathrm{mM}^{-1} \mathrm{~cm}^{-1}$ (CHANCE e Maehley, 1955).

\section{Atividade de polifenoloxidases (PPO, EC 1.10.3.1)}

O extrato enzimático foi obtido da mesma forma que para a POX. A atividade da PPO foi determinada conforme metodologias propostas por Chance e MaEhley (1955) e Kar e Mishra (1976). No ensaio colorimétrico, utilizou-se o pirogalol a $100 \mathrm{mM}$ como substrato. A reação foi composta por $520 \mu \mathrm{L}$ de água destilada, $250 \mu \mathrm{L}$ do tampão fosfato de potássio $100 \mathrm{mM}(\mathrm{pH}$ 6,8), $200 \mu \mathrm{L}$ de pirogalol $100 \mathrm{mM} \mathrm{e}$ $30 \mu \mathrm{L}$ do extrato. As leituras de absorbância foram realizadas a $420 \mathrm{~nm}$ a cada $10 \mathrm{~s}$ durante um minuto. A atividade da enzima foi medida utilizando-se para os cálculos o coeficiente de extinção molar de $2,47 \mathrm{mM}^{-1} \mathrm{~cm}^{-1}$ (Chance e Maehley, 1955).

\section{Atividade de quitinases (QUI, EC 3.2.1.14)}

O extrato enzimático foi obtido pela maceração de $0,2 \mathrm{~g}$ de folhas em $\mathrm{N}_{2}$ líquido seguida de homogeneização em $2 \mathrm{~mL}$ do meio de extração composto de tampão fosfato de sódio $50 \mathrm{mM}$ (pH 6,5), $1 \mathrm{mM}$ de PMSF e $200 \mathrm{mg}$ de PVPP. O homogeneizado foi centrifugado a $20.000 \mathrm{~g}$ por $25 \mathrm{~min}$ a $4^{\circ} \mathrm{C}$ e o sobrenadante foi utilizado no ensaio enzimático. A determinaçáo da atividade da QUI foi feita conforme metodologia proposta por RoberTs e SelitrenNikoff (1988), modificada por Harman et al. (1993), utilizando se como substrato o $p$-nitrofenil- $\beta$-D- $N$ - $N$-diacetilquitobiose (PNP) (Sigma-Aldrich, São Paulo, SP, Brasil). O meio de reação, composto por $470 \mu \mathrm{L}$ de tampão acetato de sódio $50 \mathrm{mM}$ $(\mathrm{pH} 5,0), 10 \mu \mathrm{L}$ de PNP a $2 \mathrm{mg} \mathrm{mL}^{-1}$ e $20 \mu \mathrm{L}$ do extrato vegetal, foi incubado a $37^{\circ} \mathrm{C}$ por $2 \mathrm{~h}$. A reação foi parada acrescentando-se $500 \mu \mathrm{L}$ de acetato de sódio de $50 \mathrm{mM}$ $(\mathrm{pH} \mathrm{5,0)}$. As leituras de absorbância foram realizadas a $410 \mathrm{~nm}$. Foi utilizado para o cálculo o coeficiente de extinção molar de $7 \mathrm{M}^{-1} \mathrm{~cm}^{-1} \mathrm{e}$ a atividade da QUI foi expressa em mmol de $p$-nitrofenil produzido por $\mathrm{min}^{-1} \mathrm{mg}^{-1}$ proteína.

\section{Atividade de $\beta$-1,3-glucanases (GLU, EC 3.2.1.6)}

O extrato enzimático foi obtido da mesma forma que para a QUI. A atividade da GLU foi determinada conforme metodologia descrita por LeVer (1972), com algumas modificaçôes. O ácido 3,5-dinitrosalicílico (DNS) foi usado em substituição à hidrazida do ácido $p$-hidroxibenzóico. O meio de reação, constituído de $230 \mu \mathrm{L}$ de tampão acetato de sódio $100 \mathrm{mM}$ (pH 5,0), $250 \mu \mathrm{L}$ da soluçáo de substrato da laminarina $\left(4 \mathrm{mg} \mathrm{mL}^{-1}\right)$ e $20 \mu \mathrm{L}$ do extrato vegetal, foi incubado a $45^{\circ} \mathrm{C}$ por $30 \mathrm{~min}$. Após esse período, acrescentaram-se ao meio de reação $500 \mu \mathrm{L}$ de DNS e, em seguida, essa mistura foi aquecida a $100^{\circ} \mathrm{C}$ por $5 \mathrm{~min}$. Após o resfriamento em gelo até a temperatura de $30^{\circ} \mathrm{C}$, as amostras tiveram absorbância determinada a $540 \mathrm{~nm}$ em espectrofotômetro e os resultados foram expressos em unidades de absorbância $\mathrm{min}^{-1} \mathrm{mg}^{-1}$ de proteína.

\section{Atividade da fenilalanina amônia-liase (FAL, EC 4.3.1.5)}

A atividade da FAL foi determinada pela quantificação calorimétrica do ácido trans-cinâmico liberado do substrato fenilalanina (UMEsha, 2006), com algumas modificaçóes. O extrato enzimático foi obtido pela maceração de $0,2 \mathrm{~g}$ de folhas em nitrogênio líquido seguida de homogeneização em $2 \mathrm{~mL}$ do meio de extraçáo composto de tampão de borato de sódio $50 \mathrm{mM}\left(\mathrm{pH} \mathrm{8,3),1} \mathrm{mM} \mathrm{de} \mathrm{EDTA,} 1 \mathrm{mg} \mathrm{mL}^{-1}\right.$ de tampão de ditiotreitol (DTT) e $2 \%(\mathrm{p} / \mathrm{v})$ de PVP. O homogeneizado foi centrifugado a $20.000 \mathrm{~g}$ por $20 \mathrm{~min}$ a $4^{\circ} \mathrm{C}$ e o sobrenadante foi utilizado no ensaio enzimático. $\mathrm{O}$ meio de reação, constituído de $500 \mu \mathrm{L}$ de tampão Tris- $\mathrm{HCl} 25 \mathrm{mM}$ (pH 8,8), $500 \mu \mathrm{L}$ da soluçáo de substrato $L$-fenilalanina $50 \mathrm{mM}$ e $100 \mu \mathrm{L}$ do extrato vegetal, foi incubado a $40^{\circ} \mathrm{C}$ 
por 1 hora. Após esse período, acrescentaram-se ao meio de reaçáo $200 \mu \mathrm{L}$ de $\mathrm{HCl} 0,5 \mathrm{~N}$ para paralisar a reação. A absorbância das amostras foi determinada a $290 \mathrm{~nm}$ em espectrofotômetro (Evolution 60, Thermo Scientific, Waltham, MA, EUA), contra o tampão de extração, sendo subtraído de cada amostra o valor do controle $(500 \mu \mathrm{L}$ de tampão Tris- $\mathrm{HCl} 25 \mathrm{mM} \mathrm{pH}$ 8,8, $500 \mu \mathrm{L}$ de água destilada e $100 \mu \mathrm{L}$ do extrato vegetal). Foi utilizado para o cálculo o coeficiente de extinçáo molar de $10 \mathrm{M}^{-1} \mathrm{~cm}^{-1} \mathrm{e}$ a atividade da FAL foi expressa em $\mu \mathrm{mol}$ de ácido trans-cinâmico $\mathrm{min}^{-1} \mathrm{mg}^{-1}$ de proteína.

A concentração de proteínas utilizada para o cálculo da atividade das enzimas foi obtida pelo método de BRADFORD (1976) usando albumina sérica bovina como padrão.

\section{Determinação da concentração foliar de Si}

Aos 30 dai, as folhas das plantas avaliadas no experimento sobre componentes de resistência foram coletadas, lavadas em água destilada e secas em estufa com ventilação forçada de ar a $70^{\circ} \mathrm{C}$ até atingir peso constante. Posteriormente, as folhas foram trituradas em moinho tipo Thomas-Wiley (Thomas Scientific, Swedesboro, NJ), equipado com peneira de 20 mesh para determinação da concentração foliar de Si, conforme proposto por KORNDÖRfER et al. (2004).

\section{Delineamento experimental e análise estatística dos dados}

O delineamento experimental foi o inteiramente casualizado, em esquema fatorial $2 \times 2$ com seis repetiçôes, exceto para a coleta de material para análises enzimáticas, sendo composto por quatro repetiçôes. Os fatores estudados foram dois cultivares de algodão (BRS Araçá e FM 993) e duas doses de Si (0 e 2 mmol Si L ${ }^{-1}$ ). Cada unidade experimental foi composta por um vaso plástico contendo cinco plantas de algodão. Os dados obtidos para cada variável foram submetidos à análise de variância (ANOVA) e as médias dos tratamentos, comparadas pelo test $-t(\mathrm{p} \leq 0,05)$, a interação doses de silício $\times$ cultivares foi comparada pelo teste Tukey $(\mathrm{p} \leq 0,05)$, utilizando-se o SAS versão 6.12 (SAS Institute, Inc., Cary, NC). A concentração de $\mathrm{Si}$ nos tecidos foliares foi correlacionada com os componentes de resistência do hospedeiro.

\section{RESULTADOS}

\section{PI, incidência, severidade da ramulose e concentração foliar de Si}

O fator doses de Si foi significativo para PI, incidência, AACIR e concentração foliar de $\mathrm{Si}$. O fator cultivares e a interação cultivares $\times$ doses de Si não foi significativo para as variáveis
Tabela 1. Período de incubação (PI), incidência da ramulose (I), área abaixo da curva do índice da ramulose (AACIR) e concentração foliar de Si em plantas de algodoeiro dos cultivares BRS Araçá e FM 993 crescidas em soluçáo nutritiva contendo $(+\mathrm{Si})$ ou não $(-\mathrm{Si})$ silício (Si) e inoculadas com Colletotrichum gossypii var. cephalosporioides

\begin{tabular}{|c|c|c|c|c|}
\hline \multirow{2}{*}{$\begin{array}{c}\text { Fatores } \\
\text { Silício }\end{array}$} & \multicolumn{4}{|c|}{ Variáveis } \\
\hline & $\begin{array}{c}\text { PI } \\
\text { (dias) }\end{array}$ & $\begin{array}{c}\text { Incidência } \\
(\%)\end{array}$ & AACIR & $\begin{array}{c}\mathbf{S i} \\
\left(\mathbf{g ~ k g}^{-1}\right)\end{array}$ \\
\hline$-\mathrm{Si}$ & 4,25 & 91,67 & 1441,75 & 1,4 \\
\hline$+\mathrm{Si}$ & 5,08 & 58,30 & 1188,92 & 5,9 \\
\hline DMS & $0,75^{*}$ & $22,78^{*}$ & $85,07^{*}$ & $0,9^{*}$ \\
\hline \multicolumn{5}{|l|}{ Cultivares } \\
\hline BRS Araçá & 4,66 & 75,00 & 1290,83 & 3,8 \\
\hline FM 993 & 4,66 & 75,00 & 1339,83 & 3,4 \\
\hline DMS & $0,83^{\text {ns }}$ & $27,14^{\text {ns }}$ & $85,09^{\text {ns }}$ & $2,1^{\text {ns }}$ \\
\hline C.V. (\%) & 18,97 & 35,61 & 7,66 & 28,33 \\
\hline \multicolumn{5}{|c|}{ Valores de F } \\
\hline Cultivar (C) & $0,99^{\text {ns }}$ & $0,10^{\text {ns }}$ & $1,42^{\mathrm{ns}}$ & $0,83^{\text {ns }}$ \\
\hline Silício (Si) & $5,32^{*}$ & $9,35^{* *}$ & $37,78^{* *}$ & $112,69^{* *}$ \\
\hline $\mathrm{C} \times \mathrm{Si}$ & $1,92^{\text {ns }}$ & $2,34^{\text {ns }}$ & $0,47^{n s}$ & $3,49^{\text {ns }}$ \\
\hline
\end{tabular}

** $\mathrm{e}^{*}$ significam $\mathrm{p} \leq 0,01$ e $\mathrm{p} \leq 0,05$, respectivamente; $\mathrm{C} . \mathrm{V}$. = coeficiente de variaçăo; ${ }^{\text {ns: }}$ náo significativo

avaliadas (Tabela 1). O PI aumentou significativamente em $19,5 \%$ quando foram comparadas as plantas do tratamento + Si com as do tratamento -Si (Tabela 1). A incidência da ramulose e a AACIR foram reduzidas significativamente em $64 \%$ e $18 \%$, respectivamente, quando compararam-se as plantas do tratamento $+\mathrm{Si} \mathrm{com}$ as plantas do tratamento -Si (Tabela 1). A concentração foliar de Si aumentou em $76 \%$ na presença de $\mathrm{Si}$ (Tabela 1).

\section{Correlação de Pearson}

A correlação entre a concentração foliar de Si e o PI foi positiva e significativa $(r=0,34, \mathrm{p} \leq 0,01) \mathrm{e}$, para a incidência da ramulose e a AACPR, negativa e significativa $(r=-0,44$ e $-0,70, p \leq 0,01$, respectivamente).

\section{Atividades de POX e PPO}

Nas plantas do cultivar BRS Araçá supridas com Si ocorreu aumento significativo na atividade da POX aos 20 e 30 dai, de $20 \%$ e $23 \%$, respectivamente, quando comparadas com as plantas que não receberam $\mathrm{Si}$ (Figura 1a). Nas plantas do cultivar FM 993 que receberam Si, houve aumento de $15 \%$ na atividade da POX aos 30 dai, quando comparadas as plantas que não receberam $\mathrm{Si}$ (Figura $1 \mathrm{~b}$ ).

Nas plantas do cultivar BRS Araçá supridas com Si, houve aumento significativo de $37 \%$ na atividade da PPO aos 20 dai, quando comparadas com as plantas que não receberam Si (Figura 2a). Nas plantas do cultivar FM 993 supridas com $\mathrm{Si}$, não foi constatado aumento significativo na atividade da PPO quando comparadas com as plantas não supridas com Si (Figura 2b). 


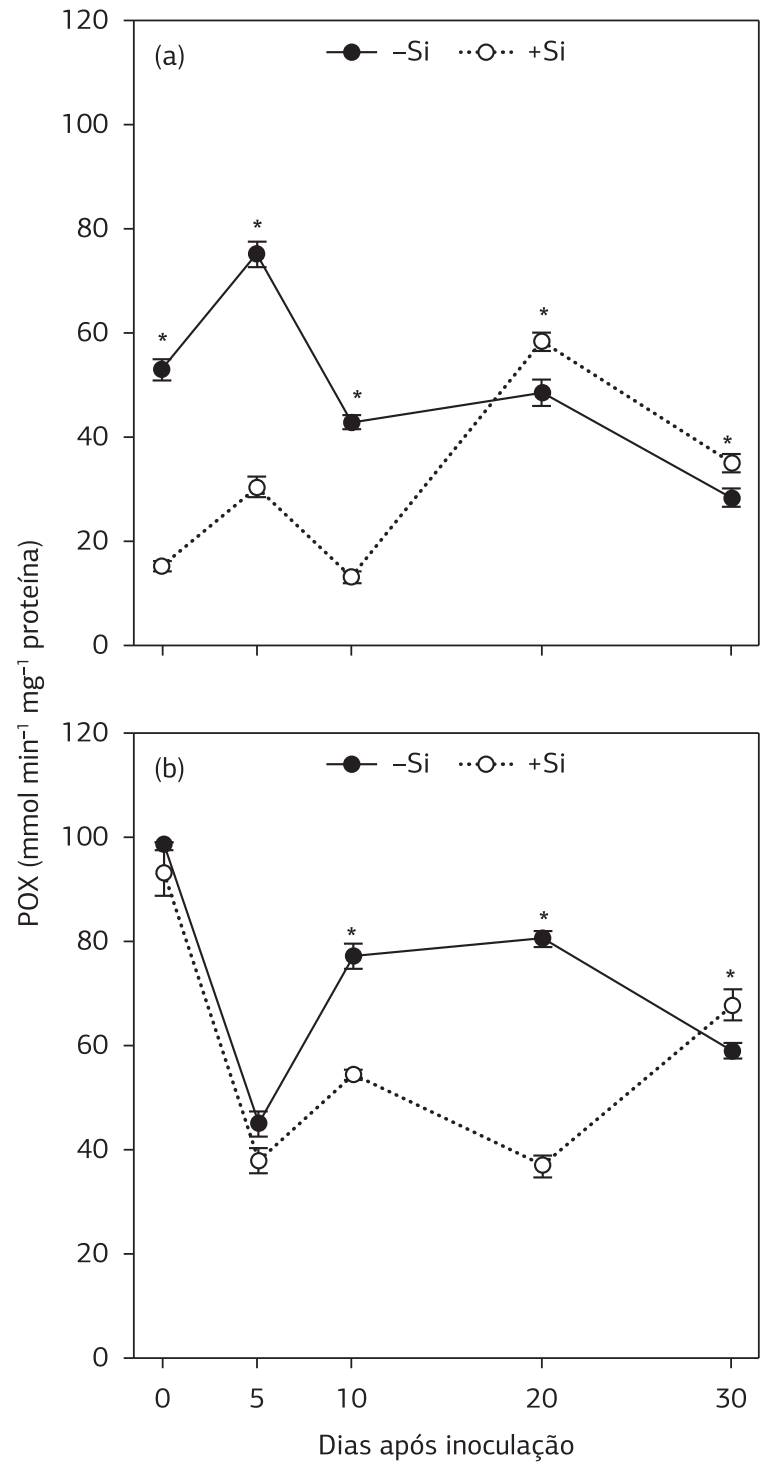

Figura 1. Atividade da peroxidase (POX) em folhas de plantas de algodáo dos cultivares BRS Araçá (a) e FM 993 (b) crescidas em solução nutritiva contendo $(+\mathrm{Si})$ ou não $(-\mathrm{Si})$ silício $(\mathrm{Si})$ e inoculadas com Colletotrichum gossypii var. cephalosporioides; cada ponto representa a média de quatro repetiçóes; barras representam o desvio padrão da média; médias dos tratamentos $-\mathrm{Si}$ e $+\mathrm{Si}$ seguidas de asterisco $\left(^{*}\right)$ são diferentes pelo teste- $t$ a $5 \%$ de significância.

\section{Atividades de QUI e GLI}

Nas plantas do cultivar BRS Araçá supridas com $\mathrm{Si}$, houve aumento significativo na atividade da QUI aos 10, 20 e 30 dai, de $415 \%$, 387\% e 58\%, respectivamente, quando comparadas com as plantas do tratamento sem Si (Figura 3a). Em plantas do cultivar FM 993 supridas com Si foi constatado aumento na atividade da QUI aos 0 e 5 dai, de $17 \%$ e $180 \%$, respectivamente, quando comparadas com as plantas do tratamento sem Si (Figura 3b).

Em plantas do cultivar BRS Araçá supridas com Si, houve aumento na atividade da GLI aos 10, 20 e 30 dai, de

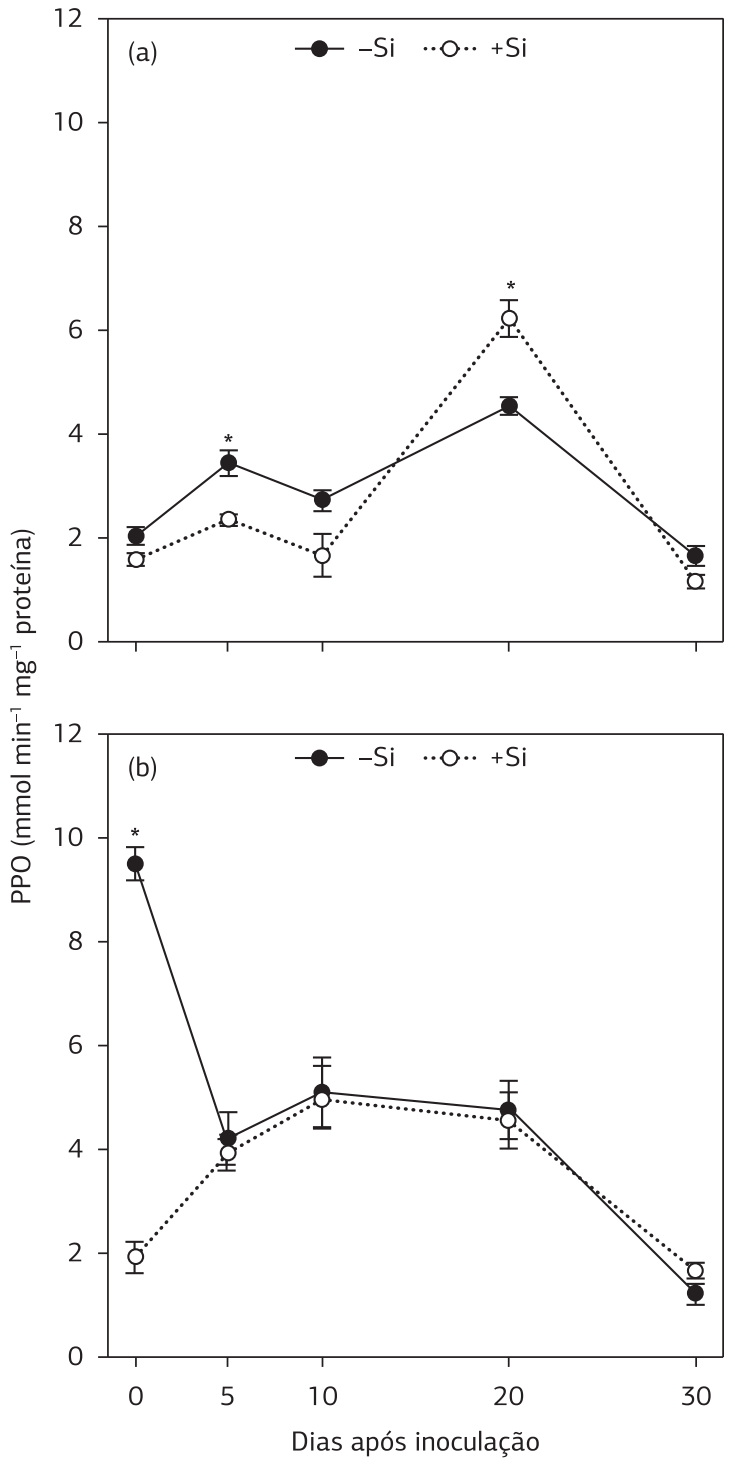

Figura 2. Atividade da polifenoloxidase (PPO) em folhas de plantas de algodáo dos cultivares BRS Araçá (a) e FM 993 (b) crescidas em solução nutritiva contendo $(+\mathrm{Si})$ ou não $(-\mathrm{Si})$ silício $(\mathrm{Si})$ e inoculadas com Colletotrichum gossypii var. cephalosporioides; cada ponto representa a média de quatro repetiçôes; barras representam o desvio padrão da média; médias dos tratamentos $-\mathrm{Si}$ e $+\mathrm{Si}$ seguidas de asterisco $\left(^{*}\right)$ sáo diferentes pelo teste- $t$ a $5 \%$ de significância.

$800 \%, 300 \%$ e $15 \%$, respectivamente, quando comparadas com as plantas do tratamento sem Si (Figura 4a). Nas plantas do cultivar FM 993 supridas com Si, ocorreu aumento na atividade da GLI aos 0 e 30 dai, de $42 \%$ e $30 \%$, respectivamente, quando comparadas com as plantas que não receberam $\mathrm{Si}$ (Figura $4 \mathrm{~b}$ ).

\section{Atividade da FAL}

Nas plantas do cultivar BRS Araçá supridas com Si, houve aumento na atividade da FAL aos 0 e 30 dai, de $576 \%$ e $30 \%$, respectivamente, quando comparadas às plantas náo 


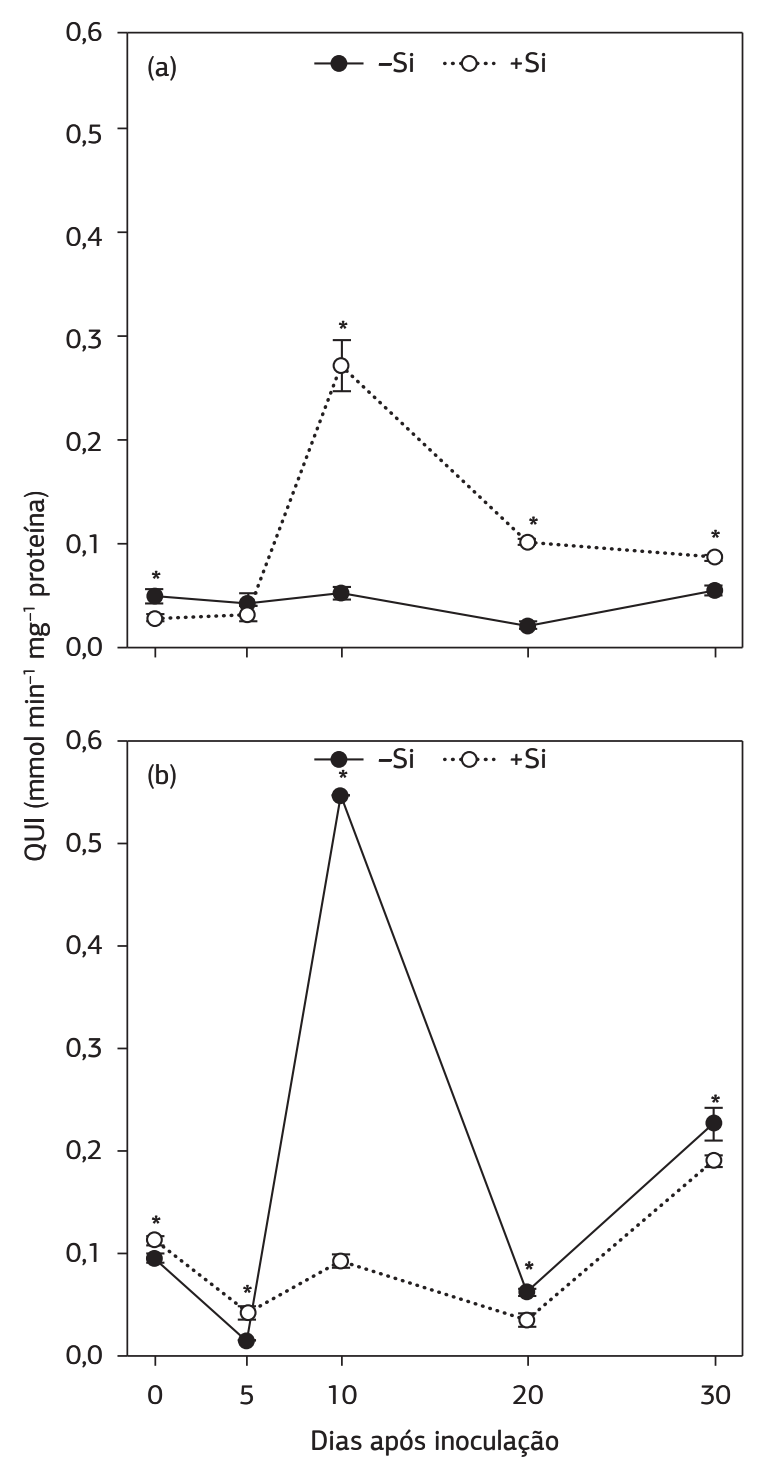

Figura 3. Atividade da quitinase (QUI) em folhas de plantas de algodão dos cultivares BRS Araçá (a) e FM 993 (b) crescidas em solução nutritiva contendo $(+\mathrm{Si})$ ou não $(-\mathrm{Si})$ silício $(\mathrm{Si})$ e inoculadas com Colletotrichum gossypii var. cephalosporioides; cada ponto representa a média de quatro repetiçóes; barras representam o desvio padrão da média; médias dos tratamentos $-\mathrm{Si}$ e $+\mathrm{Si}$ seguidas de asterisco $\left({ }^{*}\right)$ são diferentes pelo teste- $t$ a $5 \%$ de significância.

supridas com Si (Figura 5a). Para as plantas do cultivar FM 993 supridas com Si, houve aumento na atividade da FAL aos 10 e 30 dai, de $61 \%$ e $144 \%$, respectivamente, em relação às plantas do tratamento sem $\mathrm{Si}$ (Figura $5 \mathrm{~b}$ ).

\section{Concentrações de CFST e DLATG}

Nas plantas do cultivar BRS Araçá supridas com Si, a concentração de CFST apresentou aumentos significativos apenas aos 0 dai, sendo esse aumento de $15 \%$ quando comparadas com plantas náo supridas com Si (Figura 6a). Nas plantas do cultivar FM 993 supridas com Si, a concentração

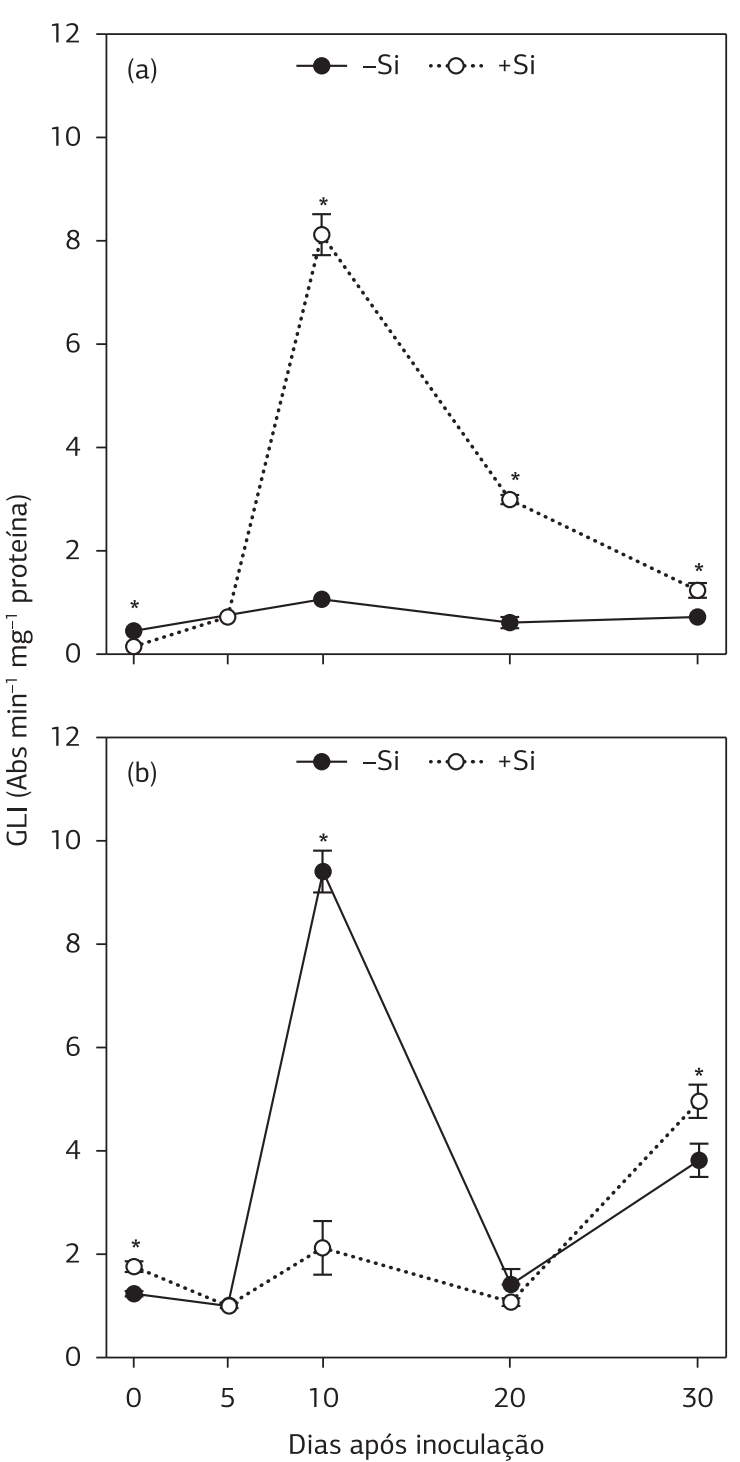

Figura 4. Atividade da glicanase (GLI) em folhas de plantas de algodão dos cultivares BRS Araçá (a) e FM 993 (b) crescidas em solução nutritiva contendo $(+\mathrm{Si})$ ou não $(-\mathrm{Si})$ silício $(\mathrm{Si})$ e inoculadas com Colletotrichum gossypii var. cephalosporioides; cada ponto representa a média de quatro repetiçóes; barras representam o desvio padrão da média; médias dos tratamentos -Si e +Si seguidas de asterisco $\left(^{*}\right)$ são diferentes pelo teste- $t$ a $5 \%$ de significância.

de CFST aumentou significativamente aos 0 e 30 dai, sendo esse aumento de $168 \%$ e $18,5 \%$, respectivamente, quando comparadas com as plantas não supridas com $\mathrm{Si}$ (Figura 6b).

Nas plantas do cultivar BRS Araçá supridas com Si, a concentração de DLATG decresceu até os 10 dai e aumentou até os 30 dai (Figura 7a), observando-se aumento significativo de $28 \%$ aos 30 dai quando comparados os tratamentos +Si e -Si. Nas plantas do cultivar FM 993 supridas com $\mathrm{Si}$, a concentração de DLATG aumentou entre 5 e 30 dai (Figura $7 \mathrm{~b}$ ), porém não se observaram diferenças significativas entre os tratamentos $+\mathrm{Si}$ e $-\mathrm{Si}$. 


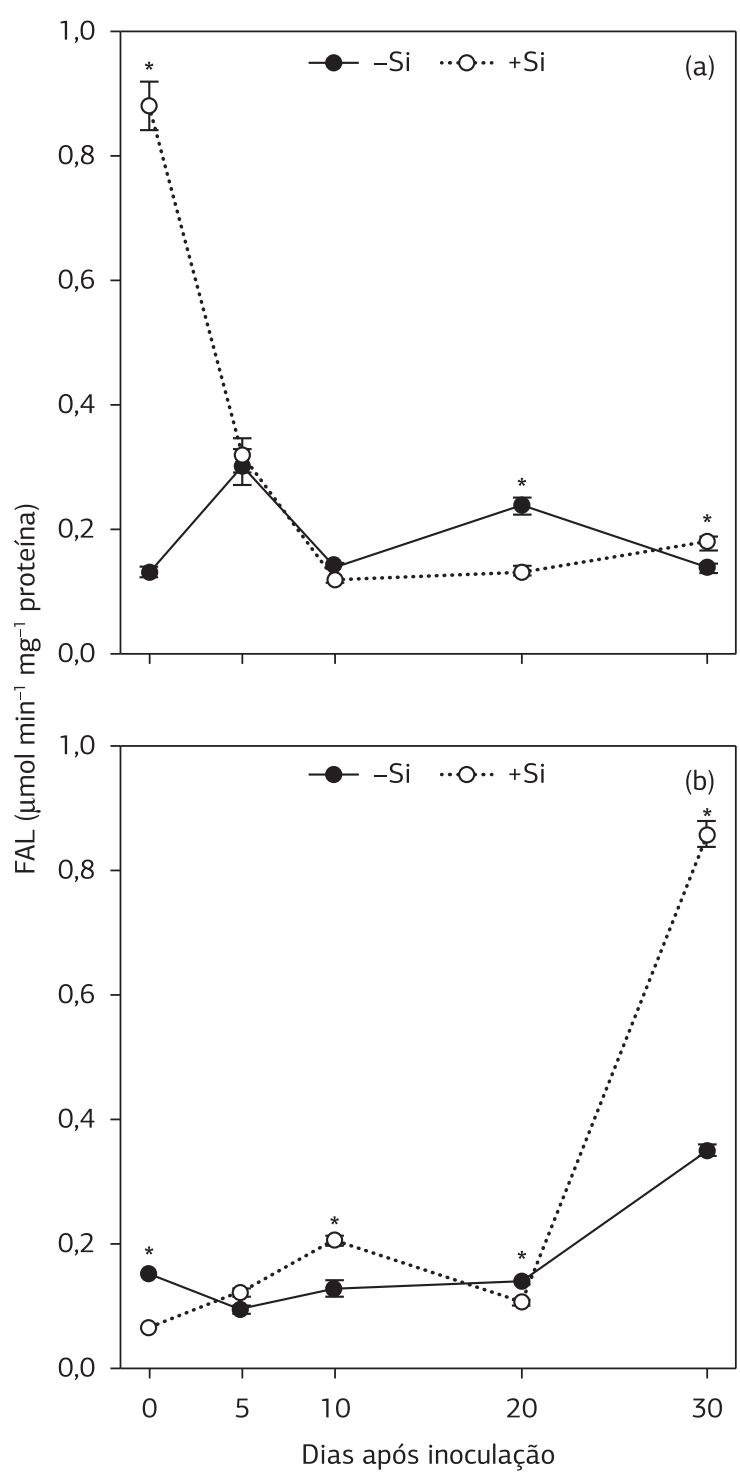

Figura 5. Atividade da fenilalanina amônia-liase (FAL) em folhas de plantas de algodão dos cultivares BRS Araçá (a) e FM 993 (b) crescidas em solução nutritiva contendo $(+\mathrm{Si})$ ou não $(-\mathrm{Si})$ silício $(\mathrm{Si})$ e inoculadas com Colletotrichum gossypii var. cephalosporioides; cada ponto representa a média de quatro repetiçóes; barras representam o desvio padrão da média; médias dos tratamentos $-\mathrm{Si}$ e $+\mathrm{Si}$ seguidas de asterisco $\left(^{*}\right)$ são diferentes pelo teste- $t$ a $5 \%$ de significância.

\section{DISCUSSÃO}

Neste estudo são apresentadas informações sobre as respostas bioquímicas de defesa do algodoeiro à infecção por C. gossypii var. cephalosporioides potencializadas pelo Si. A absorção e acúmulo de Si pelas plantas de algodoeiro impactou negativamente o progresso da ramulose, no que este estudo assemelha-se a outros que mostram os efeitos benéficos do Si no controle de doenças em culturas economicamente importantes (DatNoff et al., 2007).

O fornecimento de Si às plantas dos dois cultivares afetou o PI. Zadoks (1971) relatou que aumentos no PI podem

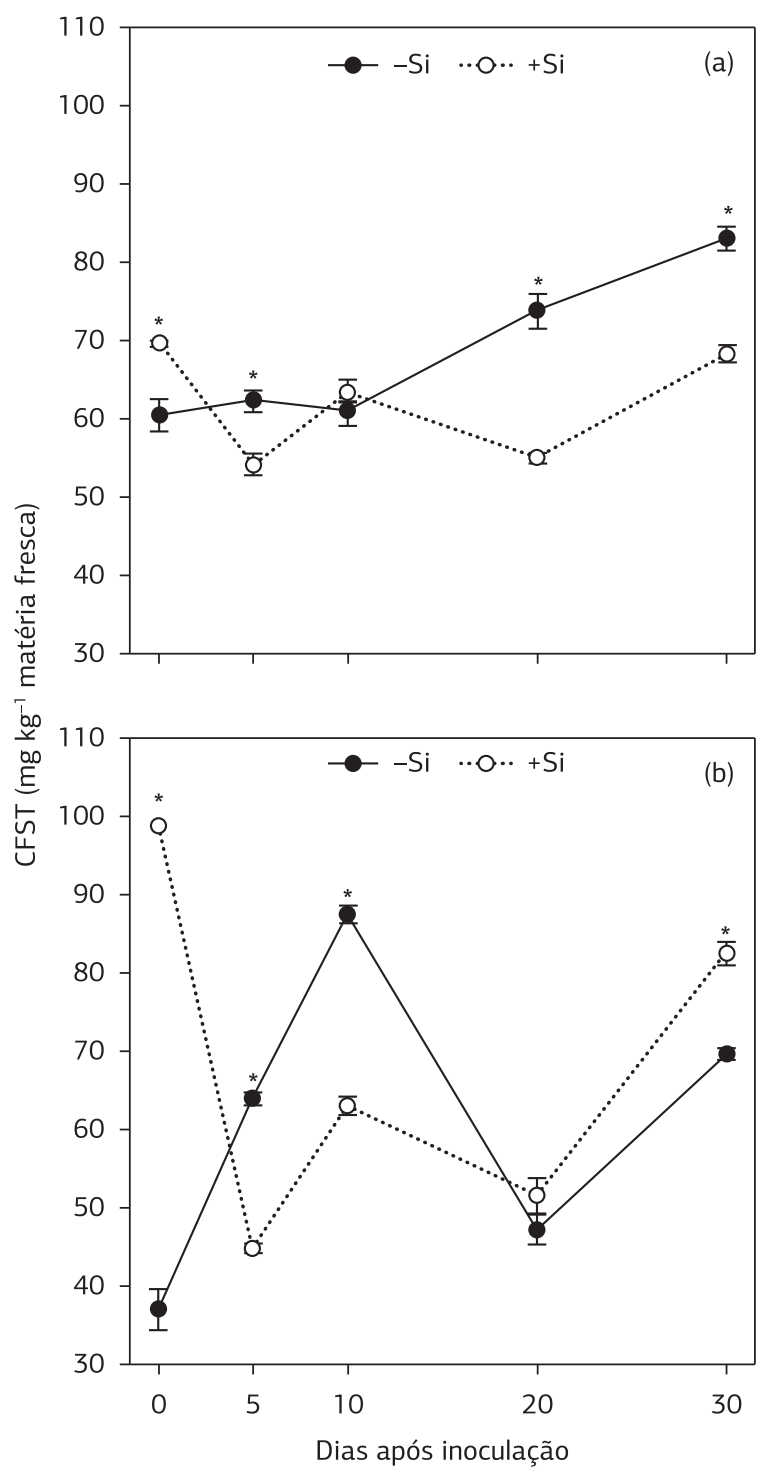

Figura 6. Concentração de compostos fenólicos solúveis totais (CFST) em folhas de plantas de algodão dos cultivares BRS Araçá (a) e FM 993 (b) crescidas em solução nutritiva contendo $(+\mathrm{Si})$ ou não $(-\mathrm{Si})$ silício (Si) e inoculadas com Colletotrichum gossypii var. cephalosporioides; cada ponto representa a média de quatro repetiçóes; barras representam o desvio padrão da média; médias dos tratamentos $-\mathrm{Si}$ e $+\mathrm{Si}$ seguidas de asterisco $\left(^{*}\right)$ são diferentes pelo teste- $t$ a $5 \%$ de significância.

reduzir o taxa de epidemia. Isso ocorre como consequência da diminuição no número de ciclos secundários do patógeno. A redução na AACIR devido ao fornecimento de $\mathrm{Si}$ sugere que esse elemento pode interferir na colonização do patógeno. O mecanismo de ação do Si sobre a redução da ramulose ainda não é conhecido. No entanto, pode-se inferir que seu efeito pode dever-se à formação de barreiras (químicas e físicas) que conferem resistência nas folhas das plantas de algodoeiro. Um dos mecanismos envolvidos na resistência das plantas mediada pelo $\mathrm{Si}$, especialmente no patossistema arroz-Pyricularia grisea, foi atribuído à deposição do Si abaixo da cutícula (KIm et al., 2002). Os resultados obtidos 


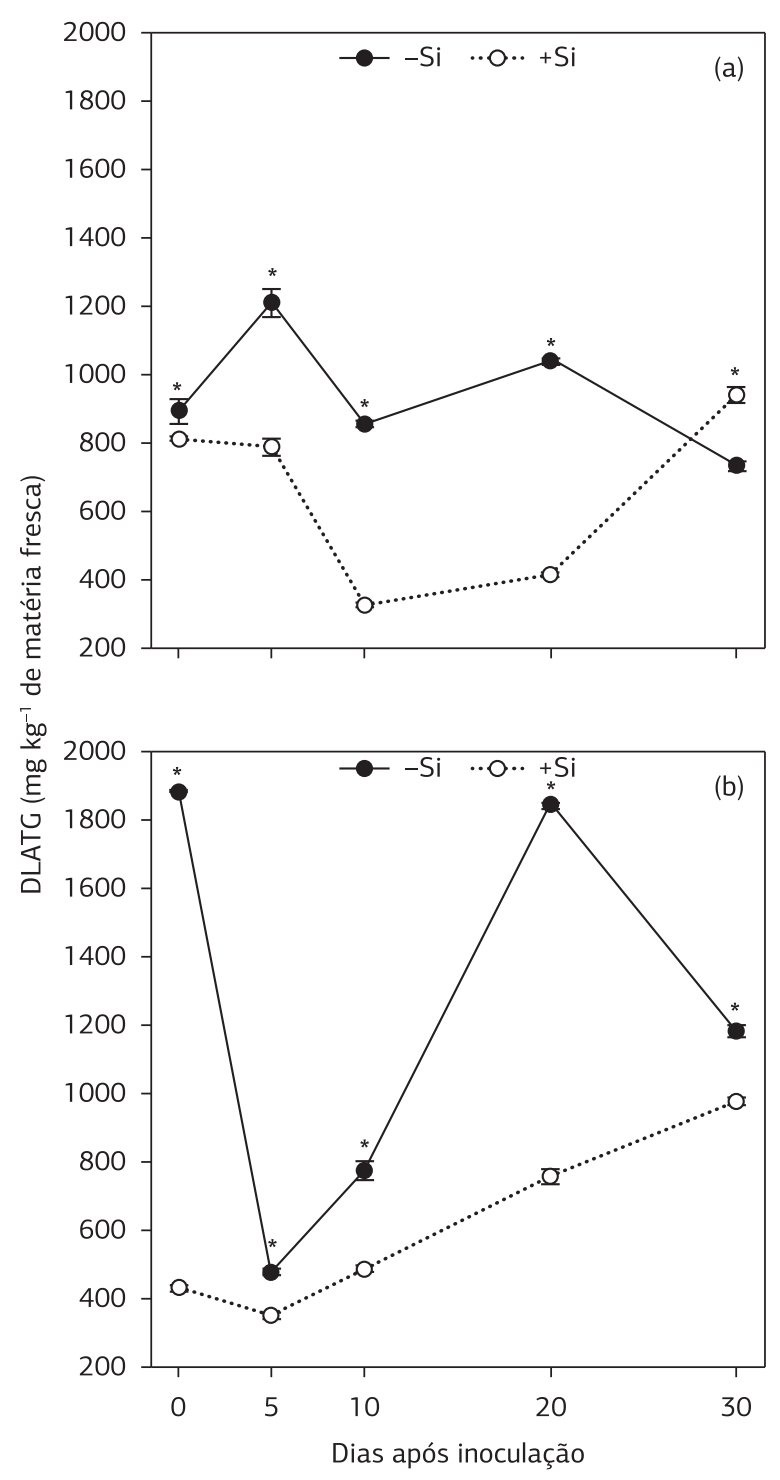

Figura 7. Concentraçáo de derivados da lignina-ácido tioglicólico (DLATG) em folhas de plantas de algodão dos cultivares BRS Araçá (a) e FM 993 (b) crescidas em solução nutritiva contendo (+Si) ou não $(-\mathrm{Si})$ silício $(\mathrm{Si})$ e inoculadas com Colletotrichum gossypii var. cephalosporioides; cada ponto representa a média de quatro repetiçóes; barras representam o desvio padrão da média; médias dos tratamentos $-\mathrm{Si} \mathrm{e}+\mathrm{Si}$ seguidas de asterisco $\left(^{*}\right)$ são diferentes pelo teste- $t$ a $5 \%$ de significância.

corroboram os encontrados por SHETTy et al. (2012), que observaram atraso no aparecimento dos sintomas e redução na severidade do míldio pulverulento em roseira suprida com Si. Resende et al. (2009) obtiveram aumento no PI e $\mathrm{PL}_{60}$ e redução da eficiência relativa de infecção e a área abaixo da curva do progresso da antracnose nas folhas de uma linhagem suscetível de sorgo com a aplicação de silicato de cálcio no solo.

No presente estudo, a concentração de CFST foi menor nas folhas das plantas supridas com Si, porém foi capaz de aumentar a resistência das plantas dos dois cultivares. Isso foi possível por os compostos fenólicos estarem associados com as defesas das plantas aos patógenos e serem encontrados tanto em interaçôes compatíveis quanto incompatíveis (NichOlson e Hammerschmidt, 1992). É relatado que a aplicação de Si pode levar a aumentos na produção de compostos fenólicos em plantas infectadas por patógenos (CARVER et al., 1998; RoDrigues et al., 2005). Os resultados obtidos neste estudo corroboram os obtidos por Domiciano et al. (2010) e Xavier FilHa et al. (2011), os quais mostraram que valores inferiores na concentração de CFST nas folhas das plantas de trigo supridas com Si foram suficientes para reduzir a área abaixo da curva de progresso da mancha marrom (AACPMM) e a área abaixo da curva de progresso da brusone (AACPB).

Nas plantas dos dois cultivares supridas com $\mathrm{Si}$ houve aumento na concentração de DLATG durante o processo infeccioso por C. gossypii var. cephalosporioides, principalmente nas plantas do cultivar FM 993. Porém, essas concentraçóes foram menores às das plantas que náo receberam $\mathrm{Si}$. O Si pode ter contribuído para a maior resistência à ramulose, com redução na AACIR nas plantas dos dois cultivares, mesmo com menor concentração de DLATG, enquanto as plantas sem Si apresentaram maiores concentraçôes de DLATG, e, nelas, a AACIR também foi maior. Os resultados deste estudo corroboram os obtidos por RodRIGUEs et al. (2005). Esses autores observaram que a produção de DLATG foi menor nas folhas das plantas de arroz do cultivar M201 (suscetível) supridas com $\mathrm{Si}$ e inoculadas com $P$. grisea. Isso mostra que, mesmo com menores concentraçôes de DLATG nas células das folhas das plantas de algodoeiro, houve impacto negativo sobre a colonização por C. gossypii var. cephalosporioides.

A atividade das enzimas POX e PPO foi maior nas folhas das plantas da BRS Araçá supridas com Si, principalmente aos 20 dai. É possível que o Si esteja potencializando a atividade dessas enzimas. Esses resultados corroboram os obtidos por Rodrigues et al. (2005), os quais demonstraram que a quantidade de transcritos do gene POX aumentou durante o processo infeccioso de $P$. grisea em plantas de arroz de cultivares com reação incompatível e compatível supridas ou não com Si. Nas folhas das plantas do cultivar FM 993 houve aumento na atividade das enzimas POX e PPO durante o processo infeccioso, porém, nas plantas supridas com $\mathrm{Si}$, a atividade dessas enzimas foi menor à observada naquelas plantas não supridas com $\mathrm{Si}$. Provavelmente, o $\mathrm{Si}$ náo potencializou a atividade da POX e PPO no cultivar FM 993. Silva et al. (2010) mostraram que a atividade da POX em plantas de algodoeiro infectadas por C. gossypii var. cephalosporioides apresentou duas tendências: maior atividade no início do processo infeccioso para os cultivares BRS Antares (resistente) e CNPA Precoce I (suscetível), enquanto os cultivares BRS Cedro (moderadamente resistente) e BRS 187 8H (moderadamente suscetível) aumentaram a atividade da POX ao longo do processo infeccioso. Com isso pode-se inferir que a atividade das enzimas PPO e POX ocorre de maneiras diferentes, de acordo com o cultivar. 
Neste estudo, a atividade da POX está associada com o aumento na concentraçáo de lignina nas folhas das plantas dos dois cultivares, supridas ou não com $\mathrm{Si}$. As POXs têm várias funçôes fisiológicas que podem contribuir para a resistência da planta a patógenos como, por exemplo, biossíntese de compostos fenólicos (Schmid e Feucht, 1980), lignificação das paredes celulares (WALTER, 1992) e inibição do crescimento fúngico (Маско et al., 1968). Enquanto isso, é provável que a PPO esteja relacionada com as defesas da planta, produzindo compostos tóxicos ao patógeno, o que evidencia-se pelas concentraçóes dos CFST. A PPO exerce um papel importante na defesa das plantas, oxidando compostos fenólicos em quinonas, as quais são tóxicas aos patógenos; as quinonas também podem ligar-se a proteínas e a carboidratos, produzindo compostos que atuam com barreira física aos patógenos (ABDEL-AAL et al., 2001).

A atividade das enzimas QUI e GLI foi maior nas plantas do cultivar BRS Araçá supridas com Si. A resistência do cultivar BRS Araçá, aparentemente, está relacionada com a maior atividade dessas enzimas nas plantas supridas com Si. Houve aumento na atividade das enzimas QUI e GLI durante o processo infeccioso porém, nas plantas do cultivar FM 993 supridas com $\mathrm{Si}$, a atividade dessas enzimas foi inferior à observada nas plantas não supridas com Si. O Si não está envolvido com o aumento na atividade dessas enzimas, porém elas integram o sistema de defesa das plantas do cultivar FM 993 à ramulose. Os resultados obtidos para as plantas do cultivar FM 993 corroboram os encontrados por Rodrigues et al. (2005), que demonstraram que, na interação compatível arroz- $M$. grisea, houve maior expressão dos genes da QUI e GLI nas plantas não supridas com Si. As enzimas QUI e GLI são importantes no sistema de defesa das plantas não só porque afetam o crescimento de fungos mas por provocarem a dissoluçáo das paredes das células fúngicas. QUI e GLI também são capazes de liberar, indiretamente, oligômeros de quitina que desencadeiam outras importantes reaçóes de defesa celular, como a produção de compostos fenólicos e o aumento na biossíntese de lignina (Sharma et al., 2011).

Nas plantas do cultivar BRS Araçá supridas com Si, a atividade da FAL foi menor dos 20 aos 30 dai, em relaçáo às plantas que não receberam Si. Por outro lado, nas plantas do cultivar FM 993 supridas com Si, a atividade da FAL foi maior. A FAL catalisa a desaminação do aminoácido $L$-fenilalanina, com a formação do ácido trans-cinâmico, que é precursor de vários tipos de compostos fenólicos, sendo a lignina o produto final (CAmpbell e Sederoff, 1996). Os resultados obtidos corroboram aqueles encontrados por Liang et al. (2005), os quais estudaram plantas de pepino supridas com Si e inoculadas com Podosphaera xanthii, observando aumento na atividade da FAL nas plantas supridas com Si quando comparadas com plantas não supridas com esse elemento. Provavelmente, a resistência exercida pelo Si no cultivar FM 993 está relacionada com a atividade da FAL, que aumenta a produção de CFST e DLATG.

Os resultados obtidos nas condiçóes deste estudo permitem inferir que plantas de algodoeiro dos dois cultivares supridas com Si foram mais resistentes à ramulose por aumento na concentração de compostos fenólicos e de derivados da LTGA, além de aumento na atividade das enzimas POX, PPO, QUI e GLI nas plantas do cultivar BRS Araçá, e das enzimas POX e FAL nas plantas do cultivar FM 993. Vale ressaltar que além desses mecanismos existem outros envolvidos na resistência do algodoeiro à ramulose que não foram estudados aqui.

\section{CONCLUSÃO}

A maior concentraçáo foliar de Si aumentou a resistência do algodoeiro à ramulose. A maior resistência do algodoeiro à ramulose potencializada pelo $\mathrm{Si}$ envolveu uma maior concentração de compostos fenólicos solúveis totais e de derivados da lignina-ácido tioglicólico nas plantas dos dois cultivares, bem como maior atividade das enzimas POX, PPO, QUI e GLI no cultivar BRS Araçá e das enzimas POX e FAL no cultivar FM 993.

\section{AGRADECIMENTOS}

À Fundação de Amparo à Pesquisa do Estado de Minas Gerais (FAPEMIG), pelo recurso financeiro (Processo APQ01072-10). Ao Conselho Nacional de Desenvolvimento Científico e Tecnológico (CNPq), pelas bolsas de doutorado e iniciação científica, concedidas a A. M. N. M. Guerra e A. F. Barros, e pelas bolsas de produtividade em pesquisa dos professores F. A. Rodrigues e P. G. Berger.

\section{REFERÊNCIAS}

ABDEL-AAL, E.S.M.; HUCL, P.; SOSULSKI F.W.; GRAF, R.; GILLOTT, C.; PIETRZAK L. Screening spring wheat for midge resistance in relation to ferulic acid content. Journal of Agricultural and Food Chemistry, v.4, p.3559-3566, 2001. http://dx.doi.org/10.1021/ jf010027h

BARBER, M.S.; RIDE, J.P. A quantitative assay for induce lignification in wounded wheat leaves and its use to survey potential elicitors of the response. Physiological and Molecular Plant Pathology, v.32, p.185-197, 1988. http://dx.doi.org/10.1016/S0885-5765(88)80015-8

BRADFORD, M.M. A rapid and sensitive method for the quantitation of microgram quantities of protein utilizing the principle of proteindye binding. Analytical Biochemistry, v.72, p.248-254, 1976. http:// dx.doi.org/10.1016/0003-2697(76)90527-3 
CAMPBELL, M.M.; SEDEROFF, R.R. Variation in lignin content and composition. Plant Physiology, v.110, p.3-13, 1996. http:// dx.doi.org/10.1104/pp.110.1.3

CARVER, T.L.W.; ROBBINS, M.P.; THOMAS, B.J.; TROTH, K.; RAISTRICK, N.; ZEYEN, R.J. Silicon deprivation enhances localized autofluorescent responses and phenylalanine ammonia-lyase activity in oat attacked by Blumeria graminis. Physiological and Molecular Plant Pathology, v.52, p.245-257, 1998. http://dx.doi.org/10.1006/ pmpp.1998.0149

CHANCE, B.; MAEHLEY, A.C. Assay of catalases and peroxidases. Methods in Enzymology, v.2, p.764-775, 1955. http://dx.doi. org/10.1016/S0076-6879(55)02300-8

CHÉRIF, M.; ASSELIM, A.; BÉLANGER, R.R. Defense responses induced bysoluble silicon in cucumber roots infected by Pythium spp. Phytopathology, v.84, p.236-242, 1994. http://dx.doi.org/10.1094/ Phyto-84-236

COSTA, A.S.; FRAGA JÚNIOR, C.G. Superbrotamento ou ramulose do algodoeiro. Campinas: Instituto Agronômico, 1937. 23p. (Boletim Técnico, n.19).

DATNOFF, L.E.; RODRIGUES, F.A.; SEEBOLD, K.W. Silicon and Plant Disease. In: DATNOFF, L.E.; ELMER, W.H.; HUBER, D.M. (Eds.). Mineral Nutrition and Plant Disease. St. Paul: The American Phytopathological Society, 2007. p.233-246.

DOMICIANO, G.P.; RODRIGUES, F.A.; VALE, F.X.R.; XAVIER FILHA, M.S.; MOREIRA, W.R.; ANDRADE, C.C.L.; PEREIRA, S.C. Wheat resistance to spot blotch potentiated by silicon. Journal of Phytopathology, v.158, p.334-343, 2010. http://dx.doi.org/10.1111/ j.1439-0434.2009.01623.x

EPSTEIN, E. Silicon. Annual Review of Plant Physiology and Plant Molecular Biology, v.50, p.641-664, 1999. PMid:15012222. http:// dx.doi.org/10.1146/annurev.arplant.50.1.641

HARMAN, G.E.; HAYES, C.K.; LORITO, M.; BROADWAY, R.M.; PIETRO, A.D.; PETERBAUER, C.; TRONSMO, A. QUItinolytic enzymes of Trichoderma harzianum: purification of QUItobiosidase and endoQUItinase. Phytopathology, v.83, p.313-318, 1993. http:// dx.doi.org/10.1094/Phyto-83-313

HOAGLAND, D.R.; ARNON, D.I. The water culture method for growing plants without soil. California Agricultural Experiment Station, v.347, p.32, 1950.

KAR, M.; MISHRA, D. Catalase, peroxidase and polyphenoloxidase activities during rice leaf senescence. Plant Physiology, v.57, p.315319, 1976. PMid:16659474 PMCid:PMC542015. http://dx.doi. org/10.1104/pp.57.2.315

KIM, S.G.; KIM, K.W.; PARK, E.W.; CHOI, D. Silicon-induced cell wall fortification of rice leaves, a possible cellular mechanism of enhanced host resistance to blast. Phytopathology, v.92, p.1095-1103, 2002. PMid:18944220. http://dx.doi.org/10.1094/PHYTO.2002.92.10.1095

KORNDÖRFER, G.H.; PEREIRA, H.S.; NOLLA, O.A. Análise de silício: solo, planta e fertilizante. Uberlândia: Grupo de Pesquisa em Silício, ICIAG, Universidade Federal de Uberlândia, 2004. 34p.

LEVER, M. A new reaction for colorimetric determination of carbohydrates. Analytical Biochemistry, v.47, p.273-279, 1972. http:// dx.doi.org/10.1016/0003-2697(72)90301-6
LIANG, Y. C.; SUN, W. C.; SI, J., RÖMHELD, V. Effects of foliarand root-applied silicon on the enhancement of induced resistance to powdery mildew in Cucumis sativus. Plant Pathology, v.54, p.678685, 2005. http://dx.doi.org/10.1111/j.1365-3059.2005.01246.x

MA, J.F.; TAKAHASHI, E. Soil, fertilizer and plant silicon research in Japan. Amsterdam: Elsevier Science Academic Press, 2002. 281p.

MACKO, V.; WOODBURY, W.; STAHMANN, M.A. The effect of peroxidase on the germination and growth on mycelium of Puccinia graminis f.sp. tritici. Phytopathology, v.58, p.1250-1254, 1968.

MARUR, C.J.; RUANO, O. A reference system of determination of cotton plant development. Revista Brasileira de Oleaginosas e Fibrosas, v.5, p.313-317, 2001.

McKINNEY, H. H. Influence of soil temperature and moisture on infection of wheat seedlings by Helminthosporium sativum. Journal of Agricultural Research, v.26, p.195-218, 1923.

MEHTA, Y. R.; ZANDONÁ, C.; BIBANCO, K.; ALMEIDA, W. P.; TEIXEIRA, E. A.; CUNHA, H. C.; ERIVALDO, J. Resposta diferencial de cultivares comerciais do algodoeiro a Colletotrichum gossypii var. cephalosporioides. Summa Phytopathologica, v.31, p.142-145, 2005.

NICHOLSON, R.L.; HAMMERSCHMIDT, R. Phenolic compound and their role in disease resistance. Annual Review of Phytopathology, v.30, p.369-389, 1992. http://dx.doi.org/10.1146/ annurev.py.30.090192.002101

RESENDE, R.R.; RODRIGUES, F.A.; SOARES, J.M.; CASELA, C.R. Influence of silicon on some components of resistance to anthracnose in susceptible and resistant sorghum lines. European Journal of Plant Pathology, v.124, p.533-541, 2009. http://dx.doi. org/10.1007/s10658-009-9430-6

ROBERTS, W.K.; SELITRENNIKOFF, C.P. Plant and bacterial quitinases differ in antifungal activity. Journal of General Microbiology, v.134, p.169-76, 1988.

RODRIGUES, F.A.; JURICK, W.M.; DATNOFF, L.E.; JONES, J.B.; ROLLINS, J.A. Silicon influences cytological and molecular events in compatible and incompatible rice-Magnaporthe grisea interactions. Physiological and Molecular Plant Pathology, v.66, p.144-159, 2005. http://dx.doi.org/10.1016/j.pmpp.2005.06.002

RODRIGUES, F.A.; McNALLY, D.J.; DATNOFF, L.E.; JONES, J.B.; LABBÉ, C.; BENHAMOU, N.; MENZIES, J.G.; BÉLANGER, R.R. Silicon enhances the accumulation of diterpenoid phytoalexins in rice: a potential mechanism for blast resistance. Phytopathology, v.94, p.177-183, 2004. PMid:18943541. http://dx.doi.org/10.1094/ PHYTO.2004.94.2.177

RODRIGUES, F.A.; BENHAMOU, N.; DATNOFF, L.E.; JONES, J.B.; BÉLANGER, R.R. Ultrastructural and cytochemical aspects of silicon-mediated rice blast resistance. Phytopathology, v.93, p.535-546, 2003. PMid:18942975. http://dx.doi.org/10.1094/ PHYTO.2003.93.5.535

SCHMID, P.S.; FEUCHT, W. Tissue-specific oxidative browning of polyphenols by peroxidase in cherry shoots. Gartenbauwissenschaft, v.45, p.68-73, 1980.

SHANER, G.; FINNEY, R.E. The effect of nitrogen fertilization on the expression of slow-mildewing resistance in Knox wheat. Phytopathology, v.67, p.1051-1056, 1977. http://dx.doi.org/10.1094/Phyto-67-1051 
SHARMA, N.; SHARMA, K.P.; GAUR, R.K.; GUPTA, V.K. Role of chitinase in plant defense. Asian Journal of Biochemistry, v.6, p.2937, 2011. http://dx.doi.org/10.3923/ajb.2011.29.37

SHETTY, R.; JENSE, B.; SHETTY, N.P.; HANSEN, M.; HANSEN, C.W.; STARKEY, K.R.; JORGENSEN, H.J.L. Silicon induced resistance against powdery mildew of roses caused by Podosphaera pannosa. Plant Pathology, v.61, p.120-131, 2012. http://dx.doi. org/10.1111/j.1365-3059.2011.02493.x

SILVA, F.A.C.; SANTOS, R.C.; AZEVEDO NETO, A.; GRANJA, M.M.C.; SOUZA, C.C.F.; MELO FILHO, P.A. Descritores bioquímicos em cultivares de algodoeiro em resposta a inoculaçáo com Colletotrichum gossypii var. cephalosporioides. Tropical Plant Pathology, v.35, p.114118, 2010.

SUASSUNA, N.D.; COUTINHO, W.M. Manejo das principais doenças do algodoeiro no cerrado brasileiro. In: FREIRE, E. C. Algodão no Cerrado do Brasil. 2.ed. Brasília: Abrapa. 2011. p.567-612.

UMESHA, S. Phenylalanine ammonia lyase in tomato seedlings and its relationships to bacterial canker disease resistance. Phytoparasitica, v.34, p.68-71, 2006. http://dx.doi.org/10.1007/BF02981341

WALTER, M.H. Regulation of lignification in defense. In: BOLLER, T.; MEINS, F. (Eds.). Genes Involved in Plant Defense. New York:
Springer-Verlag, 1992. p.327-352. PMid:1568117. http://dx.doi. org/10.1007/978-3-7091-6684-0_13

WRÓBEL-KWIATKOWSKA, M.; LOERNC-KUKULA, K.; STARZYCKI, M.; OSZMIANSKI, J.; KEPCZYNSKA, E.; SZOPA, $\mathrm{J}$. Expression of $\beta$-1,3-glucanase in flax causes increased resistance to fungi. Physiological and Molecular Plant Pathology, v.65, p.245256, 2004. http://dx.doi.org/10.1016/j.pmpp.2005.02.008

YOSHIDA, S. Chemical aspects of the role of silicon in physiology of the rice plant. Bulletin of the National Institute of Agricultural Science Series, v.15, p.1-58, 1965.

XAVIER FILHA, M.S.; RODRIGUES, F.A.; DOMICIANO, G.P.; OLIVEIRA, H.V.; SILVEIRA, P.R.; MOREIRA, W.R. Wheat resistance to leaf blast mediated by silicon. Australasian Plant Pathology, v.40, p.28-38, 2011. http://dx.doi.org/10.1007/s13313-010-0010-1

ZADOKS, J.C. Systems analysis and the dynamics of epidemics. Phytopathology, v.61, p.600-610, 1971.

ZIESLIN, N.; BEN-ZAKEN, R. Peroxidase activity and presence of phenolic substances in peduncles of rose flowers. Plant Physiology and Biochemistry, v.40, p.333-339, 1993. 